\title{
Impaired fecundity as a marker of health and survival: a Danish twin cohort study
}

\author{
L.J. Ahrenfeldt (1) 1,2,*, S. Möller ${ }^{3,4}$, M.J. Wensink (1) 1,5, \\ M.L. Eisenberg $\mathbb{1}^{6}$, \\ R. Lindahl-Jacobsen \\ Christensen \\ ${ }_{1,2,7,8}, T . K$. Jensen $\mathbb{1}^{9}$, and
} 'Unit of Epidemiology, Biostatistics and Biodemography, Department of Public Health, University of Southern Denmark, Odense,
Denmark ${ }^{2}$ The Danish Twin Registry, Department of Public Health, University of Southern Denmark, Odense, Denmark ${ }^{3}$ OPEN-Open
Patient data Explorative Network, Odense University Hospital, Odense, Denmark ${ }^{4}$ Department of Clinical Research, University of
Southern Denmark, Odense, Denmark ${ }^{5}$ Interdisciplinary Centre on Population Dynamics (CPop), University of Southern Denmark,
Odense, Denmark ${ }^{6}$ Male Reproductive Medicine and Surgery, Department of Urology and Obstetrics \& Gynecology, Stanford University
School of Medicine, Stanford, CA, USA ${ }^{7}$ Department of Clinical Biochemistry and Pharmacology, Odense University Hospital, Odense,
Denmark ${ }^{8}$ Department of Clinical Genetics, Odense University Hospital, Odense, Denmark ${ }^{9}$ Department of Clinical Pharmacology,
Farmacy and Environmental Medicine, University of Southern Denmark, Odense, Denmark

*Correspondence address. Department of Public Health, University of Southern Denmark, J. B. Winsløws Vej 9B, 5000 Odense C, Denmark. Tel: +45-6550-3844; E-mail: lahrenfeldt@health.sdu.dk (1) https://orcid.org/0000-0002-50 I8-1642

Submitted on November 26, 2020; resubmitted on March 5, 202 I; editorial decision on March 10, 2021

STUDY QUESTION: Is fecundity, measured as self-reported time to first pregnancy (TTP), a marker for subsequent health and survival? SUMMARY ANSWER: Long TTP was a marker for increased mortality among women and higher hospitalization rates for both women and men.

WHAT IS KNOWN ALREADY: Poor semen quality has been linked to increased mortality and morbidity from a wide range of diseases. Associations among fecundity, health and survival among women are still uncertain and studies on actual measures of fecundity and health outcomes are rare.

STUDY DESIGN, SIZE, DURATION: We performed a prospective cohort study of 7825 women and 6279 men, aged 18 and above with measures on first TTP, who participated in one of the Danish nation-wide twin surveys in 1994 (twins born 1953-1976) and 1998 (twins born 1931-1952). They were followed-up for mortality and hospital admissions from the interview until 2018.

PARTICIPANTS/MATERIALS, SETTING, METHODS: Twins were identified in the Danish Twin Registry and linked to Danish registers. TTP was restricted to the first pregnancy as a categorical outcome with cut-off points at 2,10 and 18 months. We analysed the association between TTP and survival using a Cox proportional hazards model estimating hazards ratios (HRs) with $95 \%$ confidence intervals (Cls). Fine-Gray survival models were used to estimate sub-hazard ratios for specific causes of death allowing for competing risks. Using negative binomial regression, we estimated incidence rate ratios (IRRs) with $95 \% \mathrm{Cls}$ for all-cause and cause-specific hospitalizations. All analyses were stratified by sex and adjusted for age at interview, birth cohorts, age at first attempt to become pregnant, smoking, years in school and BMI.

MAIN RESULTS AND THE ROLE OF CHANCE: In the total study population, $49.9 \%$ of women and $52.7 \%$ of men reported a TTP of less than 2 months, $30.8 \%$ of women and $29.6 \%$ of men reported a TTP of 2-9 months, $6.6 \%$ of women and $5.7 \%$ of men reported a TTP of $10-17$ months, and $13.3 \%$ of women and $12.0 \%$ of men reported a TTP of 18 months or more. Among 1305 deaths, we found a higher mortality for women $(H R=1.46 ; 95 \% \mathrm{Cl} 1.15,1.87)$ with a TTP of $\geq 18$ months relative to those with a TTP of $<2$ months, while the highest mortality was indicated for men with a TTP of $10-17$ months $(\mathrm{HR}=1.31 ; 95 \% \mathrm{Cl} 0.98,1.74)$. Among 53799 hospitalizations, we found an increased hospitalization rate among women $(\mathrm{HR}=1.21 ; 95 \% \mathrm{Cl} I .0-1.4 \mathrm{I})$ and men $(\mathrm{HR}=1.16 ; 95 \% \mathrm{Cl} 1.00-1.35)$ with a TTP of $\geq 18$ months, and for men with a TTP of $2-9$ months $(H R=1.14 ; 95 \% \mathrm{Cl} 1.01-1.30)$. A dose-response relationship was found for women regarding both mortality $(P=0.022)$ and hospitalizations $(P=0.018)$. Impaired fecundity was associated with a wide range of diseases and some causes of death, indicating a multi-factorial causal influence on fecundity, especially among women.

LIMITATIONS, REASONS FOR CAUTION: A major limitation was that fecundity depends on both partners, which was not considered in this study. Moreover, we could not obtain information on a number of potential confounders.

(c) The Author(s) 2021. Published by Oxford University Press on behalf of European Society of Human Reproduction and Embryology.

This is an Open Access article distributed under the terms of the Creative Commons Attribution Non-Commercial License (http://creativecommons.org/licenses/by-nc/4.0/), which permits non-commercial re-use, distribution, and reproduction in any medium, provided the original work is properly cited. For commercial re-use, please contact

journals.permissions@oup.com 
WIDER IMPLICATIONS OF THE FINDINGS: Fecundity seems positively correlated with overall health and may be a universal marker of future health and survival. These results add knowledge to the limited findings showing that reduced fecundity in women and poor semen quality in men may reflect worse health and a shorter life, particularly among women.

STUDY FUNDING/COMPETING INTEREST(S): This study was funded by NIH grant HD096468 (M.L.E., T.K.J. and R.L.J.). The authors declare that they have no competing interests.

TRIAL REGISTRATION NUMBER: N/A.

Key words: time to pregnancy / subfertility / infertility / mortality / hospitalization

\section{Introduction}

Fecundity is the individual's biologic capacity to reproduce irrespective of pregnancy intentions (Smarr et al., 2017). Time to pregnancy (TTP), defined by the time it takes for a couple to conceive when practicing unprotected intercourse, is a measure of fecundity, and the final common path of many biologic mechanisms in both sexes including semen quality and ovulation. TTP is a sensitive measure of fecundity in both women and men and is generally well recalled (Zielhuis et al., 1992; Joffe et al., 1995), with a shorter TTP indicating a higher fecundity (Christensen et al., 1998). About 15\% of couples take more than 12 months to conceive (i.e. clinical infertility; Del Giudice et al., 2020a), and it has been suggested that semen quality and fecundity have declined over recent decades (Carlsen et al., 1992; Smarr et al., 2017). The reasons for this decline are largely unknown, but may include lifestyle and behavioural factors as well as exposure to environmental chemicals (Sharma et al., 2013; Skakkebaek et al., 2016; Kim et al., 2019). A recent Danish twin study found that environmental factors specific for each twin explained around $70 \%$ of the subfecundity (defined as a TTP $>10$ months) in women and $95 \%$ of that in men. The relative contribution of additive genetic factors to TTP was around $30 \%$ in women and $5 \%$ in men (Ahrenfeldt et al., 2020).

There is growing evidence that women with an infertility diagnosis may be predisposed to develop health problems (Hanson et al., 2017). Several diseases have been linked to female subfecundity including obesity, type 2 diabetes mellitus, cardiovascular disease and polycystic ovarian syndrome (PCOS; Teede et al., 20I0; Flegal et al., 2012; Tobias et al., 2015; Hanson et al., 2017). Particularly, the health implications of PCOS have been thoroughly documented, and the findings include an increased risk of lower quality of life and higher risks of mental health challenges, diabetes, cardiovascular disease, hypertension and metabolic syndrome (Hallajzadeh et al., 2018; Amiri et al., 2020; Osibogun et al., 2020; Thong et al., 2020; Wilson and Peña, 2020; Yin et al., 202I). Other retrospective cohort studies based on insurance claims data have demonstrated that infertile women (women with an infertility diagnosis, women receiving fertility testing or fertility treatment) are at higher risk of cancer and incident chronic medical disease (Murugappan et al., 2019a,b). They are also more likely to develop diabetes, renal, liver and heart diseases, cerebrovascular disease and drug abuse compared with non-infertile women, suggesting that infertility and subfecundity in women may reflect a window to overall health (Murugappan et al., 2019a).

Studies in men from Europe and the U.S. have found associations between semen quality and subsequent morbidity Jacobsen et al., 2000; Eisenberg et al., 2013, 20I5b, 2016; Latif et al., 2017; Latif et al., 2018; Ferlin et al., 2019) and mortality (Jensen et al., 2009; Eisenberg et al., 2014; Glazer et al., 2019). A Danish retrospective cohort study followed 43277 men, who were referred for semen analysis due to fecundity problems, for 40 years and found a dose-response relationship between good semen quality and reduced mortality. Interestingly, the increased mortality associated with poor semen quality was due to a wide variety of diseases not only linked to diseases associated with poor socioeconomic status (Jensen et al., 2009). Another Danish cohort study followed 4712 men referred for possible infertility from 1977 to 2010 in the national hospitalization register, and found that men with poor semen quality had a higher mortality and hospitalization rate particularly from cardiovascular diseases and diabetes compared to men with good semen quality (Latif et al., 2017). An American study including 13027 men diagnosed with male factor infertility found that having an infertility diagnosis increased the risk of developing diabetes and ischemic heart disease by $30 \%$ and $48 \%$, respectively (Eisenberg et al., 2016).

Here we use data from two large cohorts of Danish twins (born 1931-1952 and 1953-1976) to shed light on potential health consequences of reduced fecundity. Although this study does not explicitly use a twin design, these twin cohorts include detailed information on TTP and are linked to high-quality Danish registry data. Thus, by using the Danish twins, we specifically aim to investigate the associations between self-reported time to first pregnancy and subsequent mortality and hospitalizations. We hypothesize that reduced fecundity is associated with higher mortality and hospitalization rates.

\section{Materials and methods}

\section{Setting and study population}

The present longitudinal study is based on two Danish nationwide twin cohorts. The Omnibus survey (Kyvik et al., 1995) was conducted in 1994 (between February and December) and included all twins born in 1953-1982, who were identified in the Danish Twin Registry (Skytthe et al., 20I I; Pedersen et al., 2019). The response rate of the health-related questionnaire survey was $89 \%$, which corresponded to 79\% of the Danish twin population (Christensen et al., 1998). The Middle-Aged Danish Twin study (MADT) was initiated between 1996 and 1998 by a random selection of 2640 twin pairs born 1931-1952 from the Danish Central Person Registry (Gaist et al., 2000).

The current study focuses on respondents who participated in one of the twin surveys, were 18years or older at survey intake (restricting the study population to the 1931-1976 birth cohorts), and had measures on TTP. We excluded 6282 twins who had never tried to become pregnant and 8226 twins with missing data on TTP, resulting in 
a study population of 14104 twins (3533 twins from the MADT survey and 10,57I twins from the Omnibus survey; Supplementary Fig. SI).

\section{Outcome assessment}

The Danish Twin Registry was linked to national health registers through a unique personal identification number (a CPR number) assigned to all persons alive and living in Denmark from 2 April 1968 and onwards. This unique CPR number enables linkage at the individual level between Danish nationwide administrative registers and other data sources (Thygesen et al., 20II). We used the Danish Civil Registration System (Pedersen, 20II) for information on mortality (from 1968), the Causes of Death Registry for information on death causes (Helweg-Larsen, 20II; from 1970) and the National Patient Register (Schmidt et al., 2015) for information on hospitalizations (from 1977). Causes of death were grouped according to a 49-item list from the Causes of Death Registry (Helweg-Larsen, 20I I). This list contains 49 causes of death based on the "International Classification of Diseases' (ICD8 before 1993 and ICDI0 from 1994 and onwards; eSundhed, 2020). In this study, the causes of death were further reduced to seven groups due to small numbers in some categories. Cause-specific hospitalizations were based on a grouping of 99 diagnoses, further combined into 13 main groups defined by Statistics Denmark (Statistic Denmark, 2020). The corresponding ICD-I0 codes are provided in Supplementary Tables SI and SII.

\section{Exposure assessment}

In both the MADT and the Omnibus survey data were collected on waiting time to first pregnancy. In the MADT, the question was: 'How many years and months did it take before you became pregnant?' In the MADT sample, questions regarding the first pregnancy concerned only pregnancies that did not end in an abortion or an extrauterine pregnancy. Thus, the questions in the MADT only applied to those who gave birth to one living child, to twins or triplets, or to one stillborn child. In the Omnibus, the question was: 'What year did you and your partner try to have children for the first time?' 'How did this first try end?'. The question was based on the following categories: 'never tried to become pregnant', 'became pregnant despite contraception', 'became pregnant after $\times$ months', 'stopped trying after $\times$ months', 'still trying and have now been trying for $\times$ months'. Answer categories were as follows: $<2,2-4,5-9,10-17$ and $\geq 18$ months. We combined the answer categories for people who became pregnant, those who stopped trying and those who were still trying. The distribution of TTP in the three groups can be found in Supplementary Table SIII, and the distribution of TTP in the total study population can be found in Supplementary Table SIV.

\section{Covariate assessment}

Covariates included age at first attempt to become pregnant based on calendar year, which in the MADT was the year when pregnancy number one ended, and in the Omnibus it was the year when the couple was trying to have children for the first time. Age was divided into four groups: less than 21 years, $21-25$ years, 26-30 years and 31 years and above. Birth cohorts were divided into 5 -year groups between 1931 and 1976. In the MADT survey, smoking was assessed by the question: 'At present, do you smoke?' The yes category included the answers: 'Yes, more than I cigarette, cheroot or I pipe of tobacco a day' and 'yes, but less than I cigarette, cheroot or I pipe of tobacco a day'. In the Omnibus, smoking was based on the question: 'Do you smoke?' which included three categories: 'no', 'yes, daily', 'yes, but not every day'. We combined these categories into yes (daily and almost every day) and no. Years in school were grouped into 7 years or less, 8-10years and II years or more. Body mass index (BMI) was based on self-reported measures on height and weight (weight $(\mathrm{kg})$ / height $\left.\left(\mathrm{m}^{2}\right)\right)$.

\section{Statistical analyses}

TTP was restricted to the first pregnancy and investigated among women and men with a TTP of 2-9, 10-17 and 18 months or more, relative to those with a TTP of less than 2 months (all cut-points were chosen based on the answer categories in the Omnibus). We pooled twins independently of zygosity, because a previous study on the Danish twins found no substantial evidence that fecundity of female twins is different according to zygosity or sex of the co-twin (Christensen et al., 1998). The subgroup of individuals who conceive without trying is difficult to classify regarding fecundity, as this group may include both individuals who use irregular and/or less effective contraception and individuals with high fecundity (Christensen et al., 1998). In the main analysis, we included individuals who conceived without trying if they reported a TTP. We classified them into the groups that corresponded to their reported TTP, but excluded them if they did not report a TTP (i.e. if TTP was missing).

The overall analyses were performed for both the MADT and the Omnibus separately and for the combined sample. Due to small samples in some of the subgroups, analyses of causes of death and hospitalizations were done for the combined sample alone. All analyses were stratified by sex and adjusted for birth cohort, age at first attempt to become pregnant, smoking status, years in school and BMI. In all regression analyses, we took the twin structure of the data into account by using robust standard errors clustered on the twin pair.

Time to event analyses were used, with age as the time scale, to investigate mortality by TTP. Using a Cox proportional hazards analysis, we estimated hazard ratios (HRs) with $95 \%$ confidence intervals ( $\mathrm{Cls}$ ) for all-cause mortality. In addition, we estimated sub-hazard ratios (SHRs) applying a Fine-Gray competing risk model (Fine and Gray, 1999) with the seven different causes of death as events, taking competing risk from the other death causes into account. The Cox proportional hazards assumption was verified using the log-log plot of the Kaplan-Meier survival function as well as the by Schoenfeld residuals, and all assumptions were met.

Hospitalization was measured as admission to a hospital for any reason as an inpatient. Due to sign of overdispersion, negative binomial regression was used to estimate frequency of hospitalizations calculating incidence rate ratios (IRRs) with $95 \% \mathrm{Cls}$. Also, we investigated cause-specific hospitalizations for the 13 different diagnosis groups and for diabetes separately. Follow-up started at interview and continued until death, emigration or end of follow-up (16 March 2018), whichever came first.

To investigate the robustness of the results, we performed several sensitivity analyses. First, we repeated the main analysis unadjusted, but with age as the underlying time scale, for mortality and adjusted 
only for age at interview in 5-year groups for hospitalizations (Supplementary Table SV). Second, we included all individuals who reported becoming pregnant despite the use of contraception in the lowest TTP group ( $<2$ months), also those who were excluded from the main analysis due to missing TTP (Supplementary Table SVI). Third, to investigate the associations among the youngest participants only, we made a sensitivity analysis in which all individuals were censored at age 45 years (Supplementary Table SVII). Fourth, in the MADT sample, where information was available, we repeated the main analysis further adjusting for diseases related to pregnancy as a binary variable (yes/no). Among women, the 'yes' category was given to those who answered 'yes' to at least one of the following questions: 'Have you had any diseases or problems which made it difficult for you to become pregnant?' 'Have you ever had an operation, which made it difficult for you to become pregnant?' 'Did a doctor ever tell you that you suffered from one of the following diseases?': pelvic infection, salpingitis, cyst on the ovaries, chlamydia infection, gonorrhoea, endometriosis and appendicitis with burst appendix. Similarly, a binary variable was constructed for men, with the 'yes' category including men, who reported 'no' to the question: 'Are both your testicles in your scrotum?' or reported 'yes' to both questions: 'Did you have mumps during adulthood?' 'Were your testicles affected?' or who reported 'yes' to the question: 'Have you ever had an operation for inguinal hernia, varicocele or a disease in the scrotum, penis or urethra?' (Supplementary Table SVIII). Lastly, we investigated mortality risks among twins who tried to become pregnant (women and men in the study population) relative to those who never tried to become pregnant and those with missing data on TTP (the latter two groups were excluded from the analyses; Supplementary Table SIX).

All main results were corrected for multiple testing by the HolmBonferroni method (Holm, 1979), which was done in R (version 3.6.I). The statistical software Stata (version 16.0) was used for all other analyses.

\section{Results}

\section{Baseline characteristics of study participants}

A total of $1305(9.3 \%)$ deaths of all causes were observed in 14104 twins during the 24-year follow-up period; 608 (7.8\%) women and 697 (11.1\%) men. More deaths were observed in the MADT sample (women: 362 (20.2\%), men: 465 (26.8\%)) than in the Omnibus sample (women: 246 (4.1\%), men: 232 (5.1\%); Table I). Hospitalization rates were $177 / 1000$ person-years for women and 180/1000 person-years for men. The Omnibus sample contributed with more hospitalizations than the MADT sample, although the hospitalizations rates were highest in the MADT (Table I). A total of $49.9 \%$ of women and $52.7 \%$ of men reported a TTP $<2$ months. Of these, 274 (7.1\%) women and $330(10.0 \%)$ men died. A total of $30.8 \%$ of women and $29.6 \%$ of men reported a TTP of 2-9 months. Of these, 191 (7.9\%) women and 224 (12.1\%) men died. A total of $6.6 \%$ of women and $5.7 \%$ of men reported a TTP of 10-17 months. Of these, 42 (8.2\%) women and 55 (I5.4\%) men died. A total of $13.3 \%$ of women and $12.0 \%$ of men reported a TTP of $\geq 18$ months. Of these, I0I (9.7\%) women and 88 (II.7\%) men died. Study participants were on average 39.4 years at interview (56.8years in the MADT and 33.7 years in the Omnibus; Table I).

\section{Associations with mortality}

The combined results showed an indication of a higher mortality among women reporting a TTP of 2-9 months $(\mathrm{HR}=1.06 ; 95 \% \mathrm{Cl}$ $0.88,1.28)$ and $10-17$ months $(H R=1.09 ; 95 \% \mathrm{Cl} \mathrm{0.78,} \mathrm{I.52),} \mathrm{and} \mathrm{a}$ significantly higher mortality among women reporting a TTP $\geq$ 18 months ( $\mathrm{HR}=1.46 ; 95 \% \mathrm{Cl}$ I.15, I.87), which remained significant after adjusting for multiple testing (Table II). A significant dose-response relationship was found for women $(P=0.022)$. For men, an indication was found towards higher mortality for those reporting a TTP of $10-17$ months $(\mathrm{HR}=1.31 ; 95 \% \mathrm{Cl} 0.98,1.74)$ and $\geq 18$ months $(H R=1.24 ; 95 \% \mathrm{Cl} 0.97$, I.59) compared with those reporting a TTP of $<2$ months (Table II). When investigating the associations for the MADT and the Omnibus separately, we found similar patterns with higher mortality among women reporting a TTP of $\geq 18$ months, and a significant dose-response relationship in Omnibus women $(P=0.026$; Table II). Among the seven causes of death, we found an increased risk of death among women reporting a TTP of $\geq 18$ months for pneumonia and other respiratory diseases $(\mathrm{SHR}=2.30 ; 95 \% \mathrm{Cl}$ I.04, 5.12) and an even stronger association with digestive, urinary, genital and endocrine diseases $(\mathrm{HR}=3.49 ; 95 \% \mathrm{Cl}$ I.58, 7.72), with the latter remaining significant after adjusting for multiple testing. In men, only the association with ill-defined conditions, senility, unknown cause and other diseases in the TTP group of 10-17 months was significant $(\mathrm{HR}=2.37 ; 95 \% \mathrm{Cl}$ I.20, 4.69; Table III).

\section{Associations with hospitalization}

For the combined sample, we found a dose-response relationship in women $(P=0.018)$ with the highest hospitalization rate $(I R R=1.21$; $95 \% \mathrm{Cl} I .04,1.4 \mathrm{I})$ among those with a TTP of $\geq 18$ months, and this remained significant after adjusting for multiple testing (Table II). A similar pattern was found in the MADT, with more hospitalizations in women reporting a TTP of $\geq 18$ months (IRR $=1.46 ; 95 \% \mathrm{Cl} \mathrm{I.II,}$ 1.93). A dose-response relationship was found for the Omnibus $(P=0.044)$, but with non-significant associations (Table II). In the combined sample, we found an increased risk of hospitalizations in men reporting a TTP of $2-9$ months (IRR $=1.14 ; 95 \% \mathrm{Cl} \mathrm{I.0I,} \mathrm{I.30)} \mathrm{and}$ of $\geq 18$ months (IRR $=1.16 ; 95 \% \mathrm{Cl} 1.00,1.35)$. A similar pattern was found in the Omnibus (Table II). When investigating the specific hospitalizations, we found more hospitalizations from nutritional and metabolic diseases in women with a TTP of 2-9 months (IRR $=1.54 ; 95 \%$ $\mathrm{Cl}$ I.16, 2.05) and of $\geq 18$ months (IRR $=1.69 ; 95 \% \mathrm{Cl}$ I.II, 2.57). In addition, women with a TTP of $\geq 18$ months had an increased risk of hospitalization for diseases of the respiratory organs (IRR $=1.38 ; 95 \%$ Cl I.04, 1.84), of the musculoskeletal system and connective tissue $(\mathrm{IRR}=1.29 ; 95 \% \mathrm{Cl} 1.05,1.69)$, and for symptoms, signs and ill-defined conditions (IRR = I.I7; $95 \% \mathrm{Cl}$ I.0I, I.35). Men with a TTP of $\geq 18$ months had more hospitalizations for infectious and parasitic diseases $(\mathrm{IRR}=1.66 ; 95 \% \mathrm{Cl} 1.08,1.52)$, diseases of the genito-urinary system (IRR $=1.52 ; 95 \% \mathrm{Cl} \mathrm{I.0I,} \mathrm{I.29)} \mathrm{and} \mathrm{diseases} \mathrm{of} \mathrm{the} \mathrm{skin} \mathrm{and}$ subcutaneous tissue $(\mathrm{IRR}=1.85 ; 95 \% \mathrm{Cl} 1.02,1.35)$ as well as for mental disorders (IRR $=2.14 ; 95 \% \mathrm{Cl}$ I.2I, 3.78), where a doseresponse relationship was found $(P=0.019$; Table IV). When investigating diabetes separately, we found more hospitalizations among 
Table I Baseline characteristics of 7825 women and 6279 men participating in two Danish twin surveys between I93 I and 1976.

\begin{tabular}{|c|c|c|c|c|c|c|}
\hline & \multicolumn{3}{|c|}{ Women } & \multicolumn{3}{|c|}{ Men } \\
\hline \multicolumn{7}{|l|}{ Time to pregnancy, months } \\
\hline$<2$ & $839(46.7)$ & $3023(50.1)$ & $3862(49.4)$ & $832(47.9)$ & $2477(54.5)$ & 3309 (52.7) \\
\hline $10-17$ & $113(6.3)$ & $401(6.7)$ & $514(6.6)$ & $124(7.1)$ & $234(5.2)$ & $358(5.7)$ \\
\hline$\geq 18$ & $189(10.5)$ & $850(\mid 4.1)$ & $1039(13.3)$ & $164(9.4)$ & $589(\mid 3.0)$ & $753(12.0)$ \\
\hline Age (y) at survey, mean (range) & $56.8(45.9-68.0)$ & $33.1(19.2-42.0)$ & $38.6(19.2-68.0)$ & $56.8(45.9-68.1)$ & $34.3(19.2-42.0)$ & $40.5(19.2-68.1)$ \\
\hline \multicolumn{7}{|l|}{ Birth cohort } \\
\hline $1946-1952$ & $593(33.0)$ & - & $593(7.6)$ & $576(33.2)$ & - & $576(9.2)$ \\
\hline $1953-1958$ & - & $1,819(30.2)$ & $1,819(23.3)$ & - & ।,786 (39.3) & ।,786 (28.4) \\
\hline $1959-1964$ & - & $2,584(42.9)$ & $2,584(33.0)$ & - & I,868 (4I.I) & ।,868 (29.8) \\
\hline $1965-1970$ & - & $1,460(24.2)$ & I,460 (18.7) & - & $817(18.0)$ & $817(13.0)$ \\
\hline $197 \mid-1976$ & - & $166(2.8)$ & $166(2.1)$ & - & $7 \mid(1.6)$ & $71(1.1)$ \\
\hline Age (y) at first attempt, mean (SD) & $23.9(4.0)$ & $24.6(3.7)$ & $24.5(3.8)$ & $27.0(4.5)$ & $26.6(3.8)$ & $26.7(4.0)$ \\
\hline$<21$ & $346(19.4)$ & $802(\mid 3.6)$ & I, I 48 (I4.9) & $199(4.5)$ & $67(3.9)$ & $266(4.3)$ \\
\hline $21-25$ & $9 \mid 4(5 \mid .3)$ & $2,830(47.9)$ & $3,744(48.7)$ & I,624 (36.5) & $642(37.1)$ & $2,266(36.7)$ \\
\hline $26-30$ & $402(22.6)$ & I,898 (32.1) & $2,300(29.9)$ & I,955 (44.0) & $715(4 \mid .3)$ & $2,670(43.2)$ \\
\hline$\leq 7$ & $705(39.3)$ & $48(0.8)$ & $753(9.8)$ & $743(42.9)$ & $78(1.8)$ & $821(13.3)$ \\
\hline $8-10$ & $925(51.6)$ & $2,506(42.6)$ & $3,431(44.7)$ & $797(46.0)$ & $2,816(63.2)$ & $3,613(58.4)$ \\
\hline$\geq 11$ & $162(9.0)$ & $3,332(56.6)$ & $3,494(45.5)$ & $192(\mid 1.1)$ & $\mathrm{I}, 56 \mathrm{I}(35.0)$ & I,753 (28.3) \\
\hline Missing & $4(0.2)$ & $143(2.4)$ & $147(1.9)$ & $5(0.3)$ & $87(1.9)$ & $92(1.5)$ \\
\hline Body Mass Index (BMI), median (IQR) & $23.7(21.5-26.5)$ & $21.8(20.1-24.1)$ & $22.2(20.3-24.8)$ & $25.5(23.8-27.8)$ & $24.0(22.3-25.8)$ & $24.4(22.6-23.3)$ \\
\hline Missing & $21(1.2)$ & $138(2.3)$ & $159(2.0)$ & $31(1.8)$ & $103(2.3)$ & $134(2.1)$ \\
\hline Deaths $^{a}$ & $362(20.2)$ & $246(4.1)$ & $608(7.8)$ & $465(26.8)$ & $232(5.1)$ & $697(11.1)$ \\
\hline $\begin{array}{l}\text { Number of events (hospitalization } \\
\text { rates per } 1000 \text { person-years) }{ }^{a}\end{array}$ & $9328(296)$ & $20510(149)$ & 29,838 (I77) & 9944 (333) & $14,017(136)$ & $23,96 \mid(180)$ \\
\hline
\end{tabular}


Table II Hazard ratios (HRs) and incidence rate ratios (IRRs) for mortality and hospitalizations among Danish women and men born 193 I-1976 with a time to pregnancy (TTP) of 2-9, I0-I 7 and I 8 months or more relative to those with a TTP of less than 2 months.

\begin{tabular}{|c|c|c|c|c|c|c|}
\hline \multirow[b]{2}{*}{ TTP, months } & \multicolumn{3}{|c|}{ Women } & \multicolumn{3}{|c|}{ Men } \\
\hline & MADT & Omnibus & Combined & MADT & Omnibus & Combined \\
\hline Mortality & $\mathrm{HR}(95 \% \mathrm{Cl})$ & $\mathrm{HR}(95 \% \mathrm{Cl})$ & $\mathrm{HR}(95 \% \mathrm{Cl})$ & $\mathrm{HR}(95 \% \mathrm{Cl})$ & $\mathrm{HR}(95 \% \mathrm{Cl})$ & HR (95\% Cl) \\
\hline$<2$ & I & I & I & I & I & I \\
\hline $2-9$ & $1.19(0.93,1.50)$ & $0.83(0.59,1.17)$ & $1.06(0.88,1.28)$ & $1.07(0.86,1.32)$ & I. $10(0.80,1.52)$ & $1.09(0.91,1.30)$ \\
\hline $10-17$ & $1.04(0.68,1.60)$ & $1.10(0.64,1.91)$ & $1.09(0.78,1.52)$ & $1.20(0.86,1.67)$ & $1.53(0.88,2.65)$ & I.3। $(0.98,1.74)$ \\
\hline$\geq 18$ & $1.44(1.03,2.00)$ & $1.51(1.07,2.13)$ & $1.46(1.15,1.87)^{\mathrm{a}}$ & $1.19(0.85,1.66)$ & $1.31(0.90,1.92)$ & $1.24(0.97,1.59)$ \\
\hline$P$-values for trend & 0.162 & 0.026 & 0.022 & 0.608 & 0.325 & 0.159 \\
\hline Hospitalization & IRR $(95 \% \mathrm{Cl})$ & $\operatorname{IRR}(95 \% \mathrm{Cl})$ & $\operatorname{IRR}(95 \% \mathrm{Cl})$ & $\operatorname{IRR}(95 \% \mathrm{Cl})$ & IRR (95\% Cl) & IRR (95\% Cl) \\
\hline$<2$ & I & I & I & I & I & I \\
\hline $2-9$ & I.07 $(0.90,1.27)$ & $0.93(0.81,1.06)$ & $0.97(0.87,1.09)$ & $0.99(0.84,1.18)$ & $1.19(1.01,1.40)$ & $1.14(1.01,1.30)$ \\
\hline $10-17$ & $1.13(0.80,1.60)$ & $0.89(0.73,1.08)$ & $0.95(0.80,1.12)$ & $0.92(0.69,1.23)$ & $1.06(0.80,1.40)$ & $1.03(0.83,1.27)$ \\
\hline$\geq 18$ & $1.46(1.11,1.93)^{\mathrm{a}}$ & $1.15(0.96,1.37)$ & $1.21(1.04,1.4 I)^{a}$ & $0.85(0.67,1.07)$ & $1.27(1.06,1.52)^{\mathrm{a}}$ & $1.16(1.00,1.35)$ \\
\hline$P$-values for trend & 0.062 & 0.044 & 0.018 & 0.512 & 0.031 & 0.088 \\
\hline
\end{tabular}

All results are adjusted for birth cohort, age at first attempt to become pregnant, smoking, years in school and BMI.

${ }^{a}$ Significant after adjusting for multiple testing.

HR: Hazard ratio, IRR: Incidence rate ratio, Cl: confidence interval.

Number of observations for mortality: Women (MADT: 1777, Omnibus: 5758; Combined: 7535). Men: (MADT: I726, Omnibus: 4356; Combined: 6082). Note. Each participant can contribute with more than one hospitalization. Number of observations for hospitalizations are stated in Table I.

women with a TTP of $2-9$ months $(\mathrm{IRR}=3.06 ; 95 \% \mathrm{Cl} 1.25,7.49)$ and $\geq 18$ months (IRR $=10.5$; $95 \% \mathrm{Cl} 2.75,40.0)$, whereas for men, fewer hospitalizations were found in the 2-9 months group (IRR =

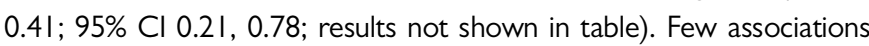
were significant after adjusting for multiple testing (Table IV).

\section{Sensitivity analyses}

Overall, the crude and the adjusted analyses were similar (Supplementary Table SV). When we included all the twins who became pregnant despite the use of contraception in the lowest TTP group ( $<2$ months), the results were similar to the overall results (Supplementary Table SVI). When investigating the association with mortality among the youngest twins (censored at age 45 years), the overall results were like the main results (Supplementary Table SVII). After adjusting for diseases related to pregnancy in the MADT sample, we found overall the same results as in the main analysis, with higher mortality and more hospitalizations among women with a TTP of $\geq 18$ months, although the association with mortality became borderline significant (Supplementary Table SVIII). No significant differences were found when comparing mortality among individuals who tried to become pregnant and those who never tried to become pregnant, but a tendency towards higher mortality among those who never tried were found both among women $(\mathrm{HR}=1.44 ; 95 \% \mathrm{Cl} 0.96,2.14)$ and among men $(H R=1.41 ; 95 \% \mathrm{Cl} 0.96,2.06)$. No differences were found among those who tried to become pregnant and those with missing data on TTP (Supplementary Table SIX).

\section{Discussion}

In this large prospective, population-based twin cohort study, reduced fecundity was associated with increased morbidity and mortality and may therefore be a general marker of health and survival. A TTP of 18 months or more was associated with increased mortality in women and with increased hospitalization rates in both sexes. The causespecific mortality and hospitalization diagnoses suggested that impaired fecundity was associated with a wide range of diseases and causes of deaths, including hospitalizations and causes of death not directly linked to the reproductive tract, such as respiratory diseases in women (mortality and hospitalizations) and mental disorders for men (hospitalizations). This indicates a multi-factorial causal influence on fecundity, especially among women.

Previous studies have reported an association between female infertility (defined as having tried to become pregnant for more than I year without success) and increased risk of cardiovascular disease and diabetes (Farland et al., 2015; Tobias et al., 2015; Mahalingaiah et al., 2017); however, we did not find any increased mortality risk of ischemic heart disease and other cardiovascular disease in women with impaired fecundity, nor did we find any increased risk of hospitalizations for diseases of the circulatory system. Diabetes was included in the category nutritional and metabolic diseases, and we found an $54 \%$ increased hospitalization risk among women reporting a TTP of 2-9 months and a $69 \%$ increased risk among those reporting a TTP of $\geq 18$ months. When investigating diabetes separately, we found an even stronger association between TTP and hospitalizations for women, supporting the indication of metabolic syndrome (e.g. higher body mass index and PCOS) as a source of impaired fecundity 


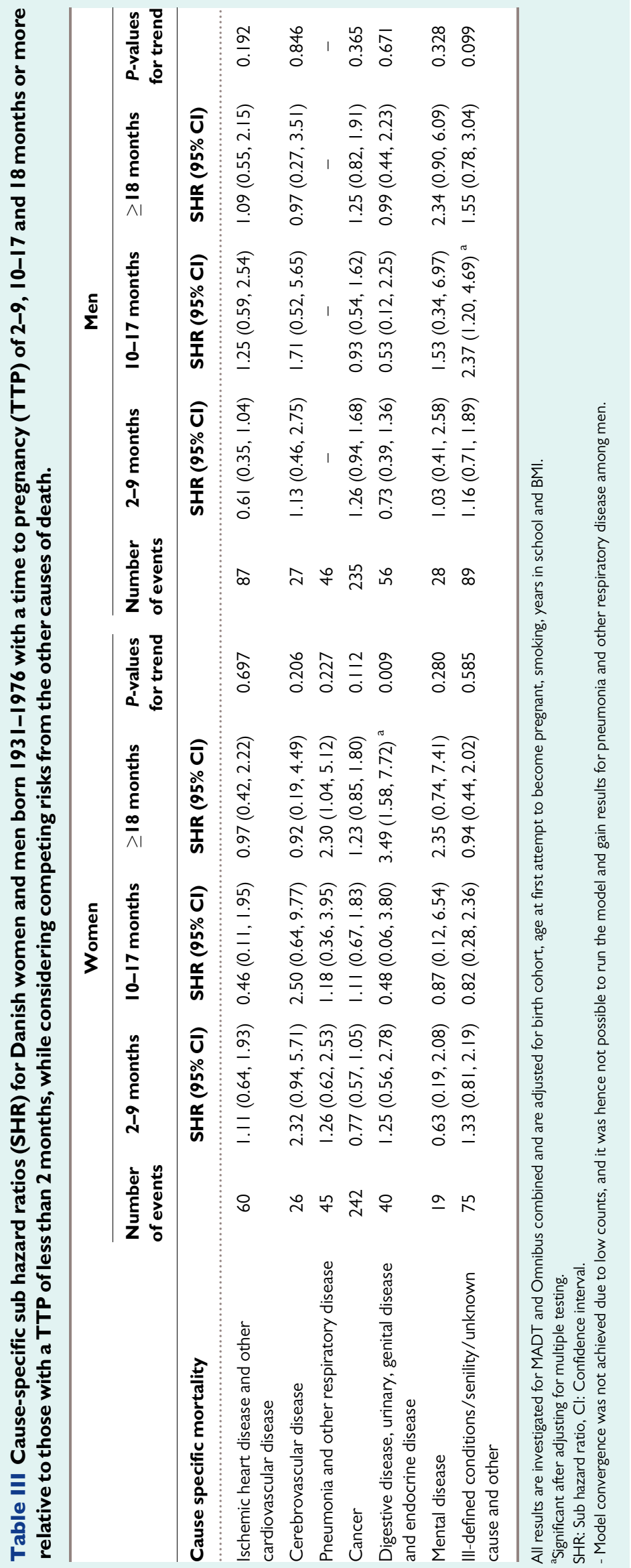




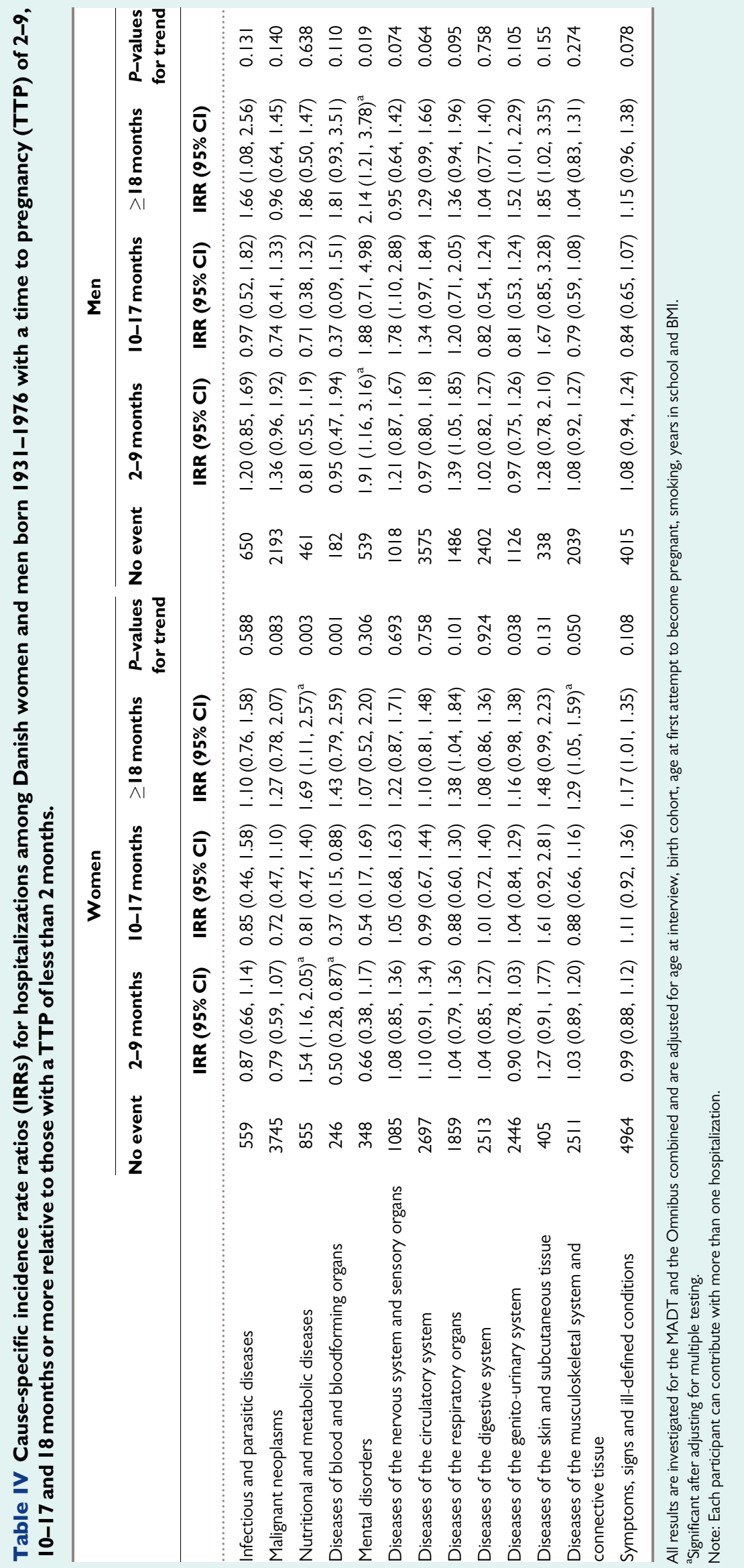


(Abraham et al., 2021, Lainez and Coss, 2019). The higher mortality and hospitalization rates from respiratory diseases in women could potentially be a marker of an association with smoking (Bolumar et al., 1996; Sapra et al., 2016); however, in the present study, adjusting for current smoking did not influence the overall results.

Our findings of increased morbidity among men with long TTP are parallel to previous work using semen quality as a measure of fecundity (Jacobsen et al., 2000; Eisenberg et al., 2013, 2015b, 2016; Latif et al., 2017; Latif et al., 2018; Ferlin et al., 2019). Moreover, our findings are in line with results from a recent review suggesting an association between male factor infertility and somatic health (Del Giudice et al., 2020b). The review suggested that infertile men appear to be at a higher risk of chronic disease regardless of socio-demographic factors, and that the literature is consistent in demonstrating higher risk of cardiovascular disease in men with impaired fertility (Del Giudice et al., 2020b). We did find significant associations with overall hospitalizations in men, and we found that a prolonged TTP in men was associated with more hospitalizations for mental disorders, diseases of the respiratory organs, infectious and parasitic diseases, disease of the genito-urinary system and diseases of the skin and subcutaneous tissue. Interestingly, we found no increased risk of any specific cause of death among men with impaired fecundity except for a higher risk of death from unknown and other causes. This was in line with results reported by Jensen et al., who did not find an increased risk for any specific cause of death among men with impaired semen quality (Jensen et al., 2009).

The association between impaired fecundity and the risk of developing a malignancy is an ongoing concern (Murugappan et al., 20l9b). In the literature, the association between male infertility and cancer varies dependent on the specific cancer examined, and results are conflicting (Del Giudice et al., 2020b). However, studies suggest that infertile women have a higher risk of certain cancers, particularly hormone-related cancers of the breast, ovaries and endometrium, than women from the general population (Murugappan et al., 2019b), and that men with impaired fecundity have a higher risk of testicular and prostate cancer (Del Giudice et al., 2020a). In this study, we found no significant associations with cancer, but indications were found towards higher mortality and more hospitalizations for cancer among women with a TTP $\geq 18$ months.

In the present study, we found the different organ systems of diseases and causes of death to be markers of fecundity in Danish twins, which supports the previous extensive literature on a complicated, interrelated causality for impaired fecundity in many contemporary human populations. The link among fecundity, mortality and morbidity could be due to genetic, hormonal, lifestyle or in utero factors (Barker, 2004; Araujo et al., 201 I; Sharma et al., 2013; Choy and Eisenberg, 2018; Ahrenfeldt et al., 2020). Low testosterone and oestradiol levels have been associated with low semen quality and fewer ovulations, and with subsequent morbidity and mortality (Haring et al., 2010; Araujo et al., 2011; Chock et al., 2012; Grin et al., 2020). Nevertheless, the association between fecundity and subsequent health may be confounded by current health and lifestyle (Latif et al., 2017). For example, obesity and smoking are known to adversely affect ovulation, semen parameters, health and life expectancy (Jensen et al., 2004; Ramlau-Hansen et al., 2007; Whitlock et al., 2009; Eisenberg et al., 2015a; Sapra et al., 2016; Lainez and Coss, 2019; Snider and Wood, 2019; Chudasama et al., 2020; de Angelis et al.,
2020). In addition, semen quality and the number of oocytes may be determined in utero and exposure to smoking in utero has been associated with reduced fecundity in both sexes (Ramlau-Hansen et al., 2007; Fowler et al., 2014).

To our knowledge, this is the first longitudinal study investigating associations between time to pregnancy and subsequent health. The main strength of this study was the population-based surveys of Danish twins linked at the individual level to several Danish registries, with complete information on mortality and hospital admissions with up to 24 years of follow-up. Because in-vitro fertilization treatment was not performed before the 1980s in Denmark, it has not affected our results. However, limitations also need mentioning. We combined two slightly different survey studies, which may have influenced the results. The MADT and the Omnibus surveys contributed $25 \%$ and $75 \%$ of the study population, respectively; however, because the MADT sample consists of the oldest birth cohorts, a higher proportion died during the study period (23.1\%) compared with the Omnibus sample (4.5\%), whereas the Omnibus survey contributed most to the hospitalization results. Compared with the Omnibus, the MADT survey was more restrictive in the pregnancies that were included (no extra-uterine pregnancies or pregnancies that ended in an abortion were included). Thus, a prolonged TTP in the Omnibus may be more discerning than a prolonged TTP in the MADT. The strong association between TTP and mortality in Omnibus women, also when we censored all persons at age 45 years, may indicate that premature mortality is also an outcome of concern in relation to TTP, which should be further investigated in future research.

Another methodological point is that the study population was conditioned on survival until interview. If impaired fecundity increases mortality (for which the evidence both from this and from previous studies is quite strong), then there will be differential survival across fecundity groups, which can bias outcomes. In this case, where we condition on survival until interview, we would expect an underestimation of the investigated associations (i.e. bias towards the null). Our results would, thus, underestimate the true effect, which may be even more pronounced among men than among women. Due to the higher mortality rate for males than females, surviving men are likely to be more physically robust (Austad and Fischer, 2016). Thus, if the weakest men especially those with long TTP died before interview, this may explain some of the null findings among men.

Another limitation in this study is that fecundity depends on both partners, which was not considered, because we had only information about the twins (i.e. not on their partners). Although TTP is a sensitive measure of fecundity and has been shown to be well recalled, men recall it less reliably than women, and the recall deteriorates with age (Joffe, 1989). Thus, results may be more uncertain in the MADT, where participants should remember their TTP for up to 49 years compared with the Omnibus, where TTP should be remembered for up to 25 years. Also, the reporting may be less reliable for men than for women, which may, at least to some degree, explain the non-significant findings regarding mortality in men. Moreover, there are potential confounders that we were not able to consider, such as lifestyle factors, behaviour, socioeconomic status, maternal diethylstilbestrol (DES) use during pregnancy (which may be relevant to a subset of the study population) and, for women, conditions such as menstrual irregularity, PCOS and/or endometriosis, which would have been ideal to take into account for the entire population and not only for the 
MADT sample. Moreover, current smoking and BMI were measured at interview and not around the time of the first attempt to become pregnancy, which may have influenced our results. Nevertheless, adjusting for diseases related to pregnancy in the MADT sample did not change the overall results, and the unadjusted and the adjusted results were similar overall, pointing towards robust findings.

Another limitation may be the generalizability of our findings. There are at least two potential confounders common to twin pregnancies that may be linked both to fecundity and to later morbidity/mortality: first, whether the twins are born small for gestational age, and, second, whether their mothers used drugs for ovarian stimulation to become pregnant. A previous study based on the Omnibus sample evaluated whether female twins from opposite-sex twin pairs have reduced fecundity compared with other female twins, and whether fecundity differs between twins and singletons. The study demonstrated similar distribution of waiting time to first pregnancy independent of zygosity (i.e. monozygotic, same-sex dizygotic and opposite-sex twins), and they found no increase in fecundity for female twins compared with singleton females, except that more twins had a TTP of less than 2 months, which was expected to be an artifact due to the data collection method. No differences were found between twins and singletons for longer waiting times (Christensen et al., 1998). Furthermore, few twins in this study are born after the 1960s, where drugs for ovarian stimulation were introduced in Denmark (Mosgaard et al., 1995) and, thus, it is unlikely that the potential use of these drugs has influenced the fecundity of the study population. Nevertheless, we do not know the proportion of same-sex couples in this study, and whether these proportions are representative for the general population. Sexual orientation may be influenced by, for example, in utero endocrine disruption (Hines, 20II), which could also affect fecundity and morbidity/ mortality. This may restrict the generalizability of our results. Moreover, this study includes only those who have tried to become pregnant, which may suggest another potential limitation of the generalizability of the results.

Another important limitation was the low number of cases in some subgroups of deaths and hospitalizations and the low number of individuals particularly in the TTP group of 10-17 months; nevertheless, despite the low numbers in some of the categories, we found a broad spectrum of associations with hospitalizations for several different diseases supporting the notion that fertility status could be used as an early surrogate of overall health.

In conclusion, in these large twin populations, we found an association between impaired fecundity and subsequent mortality for women and hospitalizations for both sexes. The broad diversity of cause-specific deaths and hospitalization diagnoses lends support for a complicated causality pattern acting on the human reproductive system. Fecundity status is, therefore, likely to be a universal marker of general health in both women and men; however, our findings need confirmation before they can be used in clinical settings to identify high-risk groups. In addition, the mechanism by which fecundity affects subsequent health needs elucidation.

\section{Supplementary data}

Supplementary data are available at Human Reproduction online.

\section{Data availability}

Data underlying this article cannot be shared publicly due to the rules of the Danish Data Protection Agency.

\section{Acknowledgements}

The authors wish to thank the twins in the MADT and the Omnibus for their participation in the surveys.

\section{Authors' roles}

L.J.A. and R.L.J. conceptualized and designed the study. L.J.A. conducted data analyses and drafted all versions of the manuscript together with R.L.J. S.M., M.J.W. and M.L.E. contributed to data analyses and interpretation of data. T.K.J. and K.C. participated in data collection. All authors revised the paper critically and approved the final version of the manuscript for submission.

\section{Funding}

This study was funded by NIH grant HD096468 (M.L.E., T.K.J. and R.L.J.).

\section{Conflict of interest}

None declared.

\section{References}

Abraham GS, Divakar PY, Valsala GA. Association of metabolic and inflammatory markers with polycystic ovarian syndrome (PCOS): an update. Arch Gynecol Obstet 2021;303:63I-643.

Ahrenfeldt LJ, Möller S, Wensink M, Jensen TK, Christensen K, Lindahl-Jacobsen R. Heritability of subfertility among Danish twins. Fertil Steril 2020; I I 4:6 I 8-627.

Amiri M, Ramezani Tehrani F, Behboudi-Gandevani S, BidhendiYarandi R, Carmina E. Risk of hypertension in women with polycystic ovary syndrome: a systematic review, meta-analysis and meta-regression. Reprod Biol Endocrinol 2020; 18:23.

Araujo AB, Dixon JM, Suarez EA, Murad MH, Guey LT, Wittert GA. Clinical review: endogenous testosterone and mortality in men: a systematic review and meta-analysis. J Clin Endocrinol Metab 201 I; 96:3007-3019.

Austad SN, Fischer KE. Sex differences in lifespan. Cell Metab 2016; 23: 1022-1033.

Barker DJP. The developmental origins of adult disease. J Am Coll Nutr 2004;23:588S-595S.

Bolumar F, Olsen J, Boldsen J. Smoking reduces fecundity: a European multicenter study on infertility and subfecundity. The European Study Group on Infertility and Subfecundity. Am J Epidemiol 1996; I43:578-587.

Carlsen E, Giwercman A, Keiding N, Skakkebaek NE. Evidence for decreasing quality of semen during past 50 years. BMJ 1992;305: 609-613. 
Chock B, Lin TC, Li CS, Swislocki A. Plasma testosterone is associated with Framingham risk score. Aging Male 2012; I 5: I34-139.

Choy JT, Eisenberg ML. Male infertility as a window to health. Fertil Steril 2018; I I 0:810-8|4.

Christensen K, Basso O, Kyvik KO, Juul S, Boldsen J, Vaupel JW, Olsen J. Fecundability of female twins. Epidemiology 1998;9: 189-192.

Chudasama YV, Khunti K, Gillies CL, Dhalwani NN, Davies MJ, Yates T, Zaccardi F. Healthy lifestyle and life expectancy in people with multimorbidity in the UK Biobank: a longitudinal cohort study. PLoS Med 2020; I 7: el 003332.

de Angelis C, Nardone A, Garifalos F, Pivonello C, Sansone A, Conforti A, Di Dato C, Sirico F, Alviggi C, Isidori A. et al. Smoke, alcohol and drug addiction and female fertility. Reprod Biol Endocrinol 2020; I 8:21.

Del Giudice F, Kasman AM, De Berardinis E, Busetto GM, Belladelli F, Eisenberg ML. Association between male infertility and malespecific malignancies: systematic review and meta-analysis of population-based retrospective cohort studies. Fertil Steril 2020a; I 44: 984-996.

Del Giudice F, Kasman AM, Ferro M, Sciarra A, De Berardinis E, Belladelli F, Salonia A, Eisenberg ML. Clinical correlation among male infertility and overall male health: a systematic review of the literature. Investig Clin Urol 2020b;6 I:355-37I.

Eisenberg ML, Betts P, Herder D, Lamb DJ, Lipshultz LI. Increased risk of cancer among azoospermic men. Fertil Steril 2013;100: 68I-685.

Eisenberg ML, Kim S, Chen Z, Sundaram R, Schisterman EF, Louis GM. The relationship between male BMI and waist circumference on semen quality: data from the LIFE study. Hum Reprod 2015a; 30:493-494.

Eisenberg ML, Li S, Behr B, Cullen MR, Galusha D, Lamb DJ, Lipshultz LI. Semen quality, infertility and mortality in the USA. Hum Reprod 2014;29:1567-1574.

Eisenberg ML, Li S, Behr B, Pera RR, Cullen MR. Relationship between semen production and medical comorbidity. Fertil Steril 2015b; 103:66-7I.

Eisenberg ML, Li S, Cullen MR, Baker LC. Increased risk of incident chronic medical conditions in infertile men: analysis of United States claims data. Fertil Steril 2016; 1 05:629-636.

eSundhed. Dokumentation. 2020. www.esundhed.dk/ Dokumentation?rid=17\&tid=98\&vid=959 (accessed 24 February 2020).

Farland LV, Grodstein F, Srouji SS, Forman JP, Rich-Edwards J, Chavarro JE, Missmer SA. Infertility, fertility treatment, and risk of hypertension. Fertil Steril 2015; 1 04:391-397.

Ferlin A, Garolla A, Ghezzi M, Selice R, Palego P, Caretta N, Di Mambro A, Valente U, De Rocco Ponce M, Dipresa S et al. Sperm count and hypogonadism as markers of general male health. Eur Urol Focus 2019;76:626-636.

Flegal KM, Carroll MD, Kit BK, Ogden CL. Prevalence of obesity and trends in the distribution of body mass index among US adults, 1999-2010. Jama 2012;307:49|-497.

Fowler PA, Childs AJ, Courant F, MacKenzie A, Rhind SM, Antignac JP, Le Bizec B, Filis P, Evans F, Flannigan S. et al. In utero exposure to cigarette smoke dysregulates human fetal ovarian developmental signalling. Hum Reprod 2014;29: I47I-1489.
Gaist D, Bathum L, Skytthe A, Jensen TK, McGue M, Vaupel JW, Christensen K. Strength and anthropometric measures in identical and fraternal twins: no evidence of masculinization of females with male co-twins. Epidemiology 2000; I I:340-343.

Glazer CH, Eisenberg ML, Tottenborg SS, Giwercman A, Flachs EM, Brauner EV, Vassard D, Pinborg A, Schmidt L, Bonde JP. Male factor infertility and risk of death: a nationwide record-linkage study. Hum Reprod 2019;34:2266-2273.

Grin L, Berkovitz-Shperling R, Zohav E, Namazov A, Leyetes S, Friedler S. Do spontaneously decreasing estradiol levels prior to triggering of ovulation adversely impact in vitro fertilization outcomes? Clin Exp Reprod Med 2020;47:213-220.

Hallajzadeh J, Khoramdad M, Karamzad N, Almasi-Hashiani A, Janati A, Ayubi E, Pakzad R, Sullman MJM, Safiri S. Metabolic syndrome and its components among women with polycystic ovary syndrome: a systematic review and meta-analysis. J Cardiovasc Thorac Res 2018;10:56-69.

Hanson B, Johnstone E, Dorais J, Silver B, Peterson CM, Hotaling J. Female infertility, infertility-associated diagnoses, and comorbidities: a review. J Assist Reprod Genet 2017;34:167-177.

Haring R, Völzke H, Steveling A, Krebs A, Felix SB, Schöfl C, Dörr $M$, Nauck $M$, Wallaschofski $H$. Low serum testosterone levels are associated with increased risk of mortality in a population-based cohort of men aged 20-79. Eur Heart J 2010;3 I: |494-1501.

Helweg-Larsen K. The Danish register of causes of death. Scand J Public Health 201 I;39:26-29.

Hines M. Prenatal endocrine influences on sexual orientation and on sexually differentiated childhood behavior. Front Neuroendocrinol 201।;32:170-182.

Holm S. A simple sequentially rejective multiple test procedure. Scand J Stat 1979;6:65-70.

Jacobsen R, Bostofte E, Engholm G, Hansen J, Olsen JH, Skakkebaek $\mathrm{NE}$, Moller $\mathrm{H}$. Risk of testicular cancer in men with abnormal semen characteristics: cohort study. BMJ 2000;32 I:789-792.

Fine JP, Gray RJ. A proportional hazards model for the subdistribution of a competing risk. J Am Stat Assoc 1999;94:496-509.

Jensen $T$, Andersson A, Jorgensen N, Andersen A, Carlsen E, Petersen J, Skakkebak N. Body mass index in relation to semen quality and reproductive hormones among 1,558 Danish men. Fertil Steril 2004;82:863-870.

Jensen TK, Jacobsen R, Christensen K, Nielsen NC, Bostofte E. Good semen quality and life expectancy: a cohort study of 43,277 men. Am J Epidemiol 2009; I 70:559-565.

Joffe M. Feasibility of studying subfertility using retrospective self reports. J Epidemiol Community Health 1989;43:268-274.

Joffe M, Villard L, Li Z, Plowman R, Vessey M. A time to pregnancy questionnaire designed for long term recall: validity in Oxford, England. J Epidemiol Community Health 1995;49:3 I4-319.

Kim YR, Pacella RE, Harden FA, White N, Toms LL. A systematic review: impact of endocrine disrupting chemicals exposure on fecundity as measured by time to pregnancy. Environ Res 2019;17I: 119-133.

Kyvik KO, Green A, Beck-Nielsen H. The new Danish Twin Register: establishment and analysis of twinning rates. Int J Epidemiol 1995;24:589-596.

Lainez NM, Coss D. REVIEW: obesity, neuroinflammation and reproductive function. Endocrinology 2019;160:2719-2736. 
Latif T, Kold Jensen T, Mehlsen J, Holmboe SA, Brinth L, Pors K, Skouby SO, Jorgensen N, Lindahl-Jacobsen R. Semen quality as a predictor of subsequent morbidity: a Danish Cohort Study of 4,7I2 men with long-term follow-up. Am J Epidemiol 2017; I86: 910-917.

Latif T, Lindahl-Jacobsen R, Mehlsen J, Eisenberg ML, Holmboe SA, Pors K, Brinth L, Skouby SO, Jørgensen N, Jensen TK. Semen quality associated with subsequent hospitalizations - Can the effect be explained by socio-economic status and lifestyle factors? Andrology 2018;6:428-435.

Mahalingaiah S, Sun F, Cheng JJ, Chow ET, Lunetta KL, Murabito JM. Cardiovascular risk factors among women with self-reported infertility. Fertil Res Pract 2017;3:7.

Mosgaard B, Lidegaard O, Andersen AN. Use of fertility drugs in Denmark 1973-1993. An analysis based on sale statistics. Acta Obstet Gynecol Scand 1995;74:6|4-618.

Murugappan G, Li S, Lathi RB, Baker VL, Eisenberg ML. Increased risk of incident chronic medical conditions in infertile women: analysis of US claims data. Am J Obstet Gynecol 2019a;220: 473.e47I-473.e4I4.

Murugappan G, Li S, Lathi RB, Baker VL, Eisenberg ML. Risk of cancer in infertile women: analysis of US claims data. Hum Reprod 2019b;34:894-902.

Osibogun O, Ogunmoroti O, Michos ED. Polycystic ovary syndrome and cardiometabolic risk: opportunities for cardiovascular disease prevention. Trends Cardiovasc Med 2020;30:399-404.

Pedersen CB. The Danish civil registration system. Scand J Public Health 201 I;39:22-25.

Pedersen DA, Larsen LA, Nygaard M, Mengel-From J, McGue M, Dalgård C, Hvidberg L, Hjelmborg J, Skytthe A, Holm NV. et al. The Danish Twin Registry: an updated overview. Twin Res Hum Genet 2019;22:499-499.

Ramlau-Hansen $\mathrm{CH}$, Thulstrup AM, Aggerholm AS, Jensen MS, Toft $G$, Bonde JP. Is smoking a risk factor for decreased semen quality? A cross-sectional analysis. Hum Reprod 2007;22: 188-196.

Sapra KJ, Barr DB, Maisog JM, Sundaram R, Buck Louis GM. Timeto-pregnancy associated with couples' use of tobacco products. Nicotine Tob Res 2016; 18:2154-216I.

Schmidt M, Schmidt SA, Sandegaard JL, Ehrenstein V, Pedersen L, Sorensen HT. The Danish National Patient Registry: a review of content, data quality, and research potential. Clin Epidemiol 2015; 7:449-490.

Sharma R, Biedenharn KR, Fedor JM, Agarwal A. Lifestyle factors and reproductive health: taking control of your fertility. Reprod Biol Endocrinol 20। 3; I I:66.
Skakkebaek NE, Rajpert-De Meyts E, Buck Louis GM, Toppari J, Andersson A-M, Eisenberg ML, Jensen TK, Jørgensen N, Swan SH, Sapra KJ. et al. Male reproductive disorders and fertility trends: influences of environment and genetic susceptibility. Physiol Rev 2016;96:55-97.

Skytthe A, Kyvik KO, Holm NV, Christensen K. The Danish Twin Registry. Scand J Public Health 201 I;39:75-78.

Smarr MM, Sapra KJ, Gemmill A, Kahn LG, Wise LA, Lynch CD, Factor-Litvak P, Mumford SL, Skakkebaek NE, Slama R. Is human fecundity changing? A discussion of research and data gaps precluding us from having an answer. Hum Reprod 2017;32: 499-504.

Snider AP, Wood JR. Obesity induces ovarian inflammation and reduces oocyte quality. Reproduction 2019; I58: R79-R90.

Statistic Denmark. IND0I: Admissions by region, diagnosis (99 groups), age and sex. 2020. StatBank Denmark. https://www.stat bank.dk/INDOI (accessed 24 February 2020).

Teede H, Deeks A, Moran L. Polycystic ovary syndrome: a complex condition with psychological, reproductive and metabolic manifestations that impacts on health across the lifespan. BMC Med 2010; 8:41.

Thong EP, Codner E, Laven JSE, Teede H. Diabetes: a metabolic and reproductive disorder in women. Lancet Diabetes Endocrinol 2020; 8: 134-|49.

Thygesen LC, Daasnes C, Thaulow I, Brønnum-Hansen $\mathrm{H}$. Introduction to Danish (nationwide) registers on health and social issues: structure, access, legislation, and archiving. Scand J Public Health 2011;39:12-16.

Tobias DK, Gaskins AJ, Missmer SA, Hu FB, Manson JE, Buck Louis GM, Zhang C, Chavarro JE. History of infertility and risk of type 2 diabetes mellitus: a prospective cohort study. Diabetologia 2015; 58:707-7। 5.

Whitlock G, Lewington S, Sherliker P, Clarke R, Emberson J, Halsey J, Qizilbash N, Collins R, Peto R, Prospective Studies Collaboration. Body-mass index and cause-specific mortality in 900 000 adults: collaborative analyses of 57 prospective studies. Lancet 2009;373: 1083-1096.

Wilson NA, Peña AS. Quality of life in adolescent girls with polycystic ovary syndrome. I Paediatr Child Health 2020;56: |35|-1357.

Yin X, Ji Y, Chan CLW, Chan CHY. The mental health of women with polycystic ovary syndrome: a systematic review and metaanalysis. Arch Womens Ment Health 2021;24: I I-27.

Zielhuis GA, Hulscher ME, Florack El. Validity and reliability of a questionnaire on fecundability. Int J Epidemiol 1992;2 I: | I5।-| | 56. 